\title{
P-ZnO/n-Si Photodiodes Prepared by Ultrasonic Spraying Pyrolysis Method
}

\author{
Lung-Chien Chen* and Chun-Nan Pan
}

Department of Electro-optical Engineering, National Taipei University of Technology, 1, sec.3, Chung-Hsiao E. Rd., Taipei 106, Taiwan, Republic of China

\begin{abstract}
ZnO}$ ultraviolet (UV)/visible photodiodes were fabricated. The N-In codoped p-type ZnO films were deposited on (111)-oriented silicon substrate by ultrasonic spraying pyrolysis method. It was found the photocurrent approximately $3.9 \times 10^{-7} \mathrm{~A}$ at a bias of $1 \mathrm{~V}$ and a photocurrent to dark current contrast ratio higher than around two orders of magnitude. The photodiodes exhibited two higher responsive regions denoted as A and B, respectively. Region A at wavelength from $400 \mathrm{~nm}$ to $700 \mathrm{~nm}$ was owing to $\mathrm{ZnO}$ film absorption occurring through the band-to-deep level, and region B at wavelength from $700 \mathrm{~nm}$ to $1000 \mathrm{~nm}$ was owing to Si substrate absorption occurring through the band edge.
\end{abstract}

Keywords: Zinc oxide, spraying pyrolysis method, photodiodes.

\section{INTRODUCTION}

Zinc oxide $(\mathrm{ZnO})$ has been regarded as promising materials for optical devices, due to its wide direct band gap energy of $3.37 \mathrm{eV}$ and large exciton binding energy of $60 \mathrm{meV}$ [1-3]. Therefore, $\mathrm{ZnO}$ has a potential for light-emitting diodes (LEDs), laser diodes (LDs) and ultraviolet (UV) detecting devices [3-6]. A variety of deposition techniques have been employed for the growth of $\mathrm{ZnO}$ layers, including metalorganic chemical vapor deposition (MOCVD) [7], plasma-assisted molecular beam epitaxy (PA-MBE) [8], pulsed laser deposition (PLD) [9], and spray pyrolysis method $[10,11]$. The synthesis of p-type $\mathrm{ZnO}$ films with acceptable stability and reproducibility by means of indium and nitrogen codoping has recently been demonstrated $[12,13]$.

ZnO photoconductors, Schottky diodes, metalsemiconductor-metal (MSM) photodiodes, and phototransistors detecting in the UV region have also been demonstrated [14-19]. Si-based photodiodes was usually employed for the detecting in the UV/visible region. However, the responsibility of Si-based photodiodes is relatively week in the UV/blue region, such as less than $0.1 \mathrm{~A} / \mathrm{W}$ at $400 \mathrm{~nm}$ [20].

This article reports a $\mathrm{p}-\mathrm{ZnO} / \mathrm{n}$-Si heterostructure photodiode. An N-In codoped p-type was deposited on a (111)oriented silicon substrate by ultrasonic spraying pyrolysis method. The growth and crystallinity of the $\mathrm{ZnO}$ films were studied. Finally, we report the fabrication and performance of the $\mathrm{p}-\mathrm{ZnO} / \mathrm{n}-\mathrm{Si}$ heterostructure photodiode.

\section{EXPERIMENTAL}

In the study, $\mathrm{N}-\mathrm{In}$ codoped $\mathrm{ZnO}$ films were deposited by ultrasonic spray pyrolysis method at atmosphere on (111)oriented silicon substrate. Three kinds of aqueous solution,

*Address correspondence to this author at the Department of Electro-optical Engineering, National Taipei University of Technology, 1, sec.3, ChungHsiao E. Rd., Taipei 106, Taiwan, Republic of China; Tel: +886-2-27712171; Fax: +886-2-8773-3216; E-mail: ocean@ntut.edu.tw
$\mathrm{Zn}\left(\mathrm{CH}_{3} \mathrm{COO}\right)_{2} \cdot 2 \mathrm{H}_{2} \mathrm{O}(0.5 \mathrm{~mol} / \mathrm{l}), \mathrm{CH}_{3} \mathrm{COONH}_{4}(2.5 \mathrm{~mol} / \mathrm{l})$, and $\mathrm{In}\left(\mathrm{NO}_{3}\right)_{3}(0.5 \mathrm{~mol} / \mathrm{l})$, were chosen as the source of zinc, nitrogen, and indium, respectively. The atomic ratio of $\mathrm{Zn} / \mathrm{N}$ is $1: 2$ for $\mathrm{N}$-doped film, and $\mathrm{Zn} / \mathrm{N} / \mathrm{In}$ is $1: 2: 0.15$ for $\mathrm{N}-\mathrm{In}$ codoped film [12]. The n-type $\operatorname{Si}(111)$ wafers $(\rho=0.005 \Omega$ $\mathrm{cm}$ ) were used as the substrates, which were etched with $\mathrm{HCl}$ for $5 \mathrm{~min}$ prior to the deposition. The aerosol of precursor solution was generated by the commercial ultrasonic nebulizer. P-type $\mathrm{N}$-In codoped $\mathrm{ZnO}$ films were obtained during the substrate heated at $650{ }^{\circ} \mathrm{C}$, and examined by Hall measurement (on sapphire substrate). The hole concentration and mobility of $\mathrm{p}-\mathrm{ZnO}$ were around $1 \times 10^{17} \mathrm{~cm}^{-3}$ and approximately $46 \mathrm{~cm}^{2} / \mathrm{V}-\mathrm{s}$, respectively.

After there, fabrication of $\mathrm{p}-\mathrm{ZnO} / \mathrm{n}-\mathrm{Si}$ heterostructures was accomplished. The films' crystallinities were studied by $\mathrm{X}$-ray diffraction $(\mathrm{XRD})$ using a rotating anode Rigacu $\mathrm{x}$-ray diffractometer with $\mathrm{Cu}-\mathrm{K} \alpha_{1}$ radiation of $1.54 \AA$, radiation generated at $40 \mathrm{kV}$ and $50 \mathrm{~mA}$, and the films had a polycrystalline structure. The $\mathrm{Ni} / \mathrm{Au}$ ohmic contact layer was evaporated onto the p-type $\mathrm{ZnO}$ film as the anode electrode, and a $\mathrm{Ti} / \mathrm{Pt} / \mathrm{Au}$ electrode was formed on the backside of the n-type $\mathrm{Si}$ substrate as the cathode electrode. Fig. (1a) shows the cross section of the completed structure. Fig. (1b) shows the current-voltage $(I-V)$ for ohmic check of $\mathrm{Au} / \mathrm{Ni} / \mathrm{p}-\mathrm{ZnO}$ and $\mathrm{Au} / \mathrm{Pt} / \mathrm{Ti} / \mathrm{n}-\mathrm{Si}$ structures, respectively. Subsequently, the photodiode chip was bonded on TO-18 can to measure the dark and illuminated current-voltage $(I-V)$ characteristics. A $30 \mathrm{~W}$ deuterium lamp and $35 \mathrm{~W}$ halogen lamp were used as the light source for the spectral responsivity studies. All measurement was carried out at room temperature.

\section{RESULTS AND DISCUSSION}

Fig. (2) shows a cross-sectional SEM image of the layer of p-type $\mathrm{ZnO}$ film deposited on (111)-oriented Si substrate. The $\mathrm{ZnO}$ film with thickness of about $1.3 \mu \mathrm{m}$ was formed on silicon substrate. The interface between the $\mathrm{ZnO}$ film and $\mathrm{Si}$ substrate is flat and free from inclusions. Fig. (3) shows a typical X-ray diffraction (XRD) pattern of $\mathrm{ZnO}$ film deposited on (111)-oriented Si substrate prepared by ultrasonic 
spraying pyrolysis method. Three dominant diffraction peaks, $\mathrm{ZnO}(100)\left(2 \theta=32.04^{\circ}\right), \mathrm{ZnO}(002)\left(2 \theta=34.84^{\circ}\right)$, and $\mathrm{ZnO}(101)\left(2 \theta=36.6^{\circ}\right)$, are observed. The lattice parameters are found to be $\mathrm{a}=3.222 \AA$ and $\mathrm{c}=5.147 \AA$. The film demonstrated a polycrystalline structure.

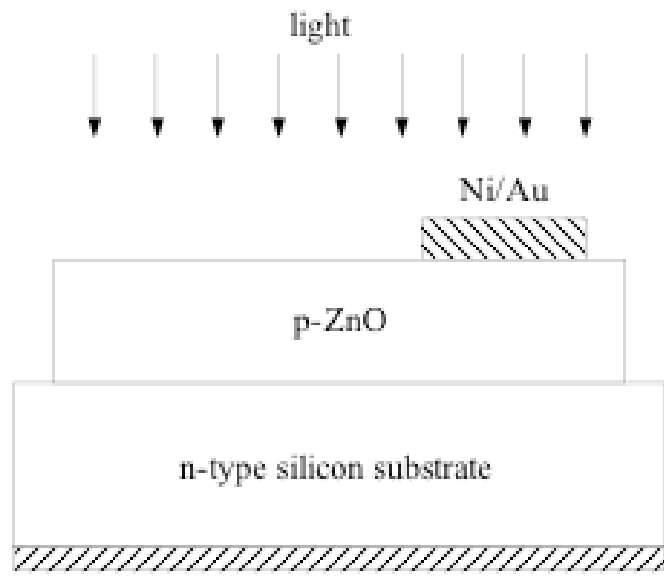

$\mathrm{Ti} / \mathrm{Pt} / \mathrm{Au}$

(a)

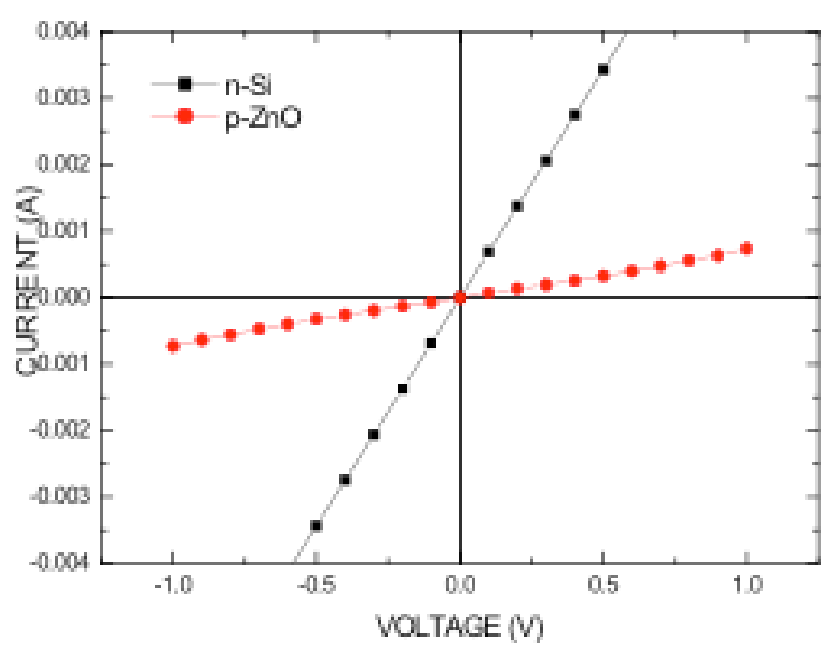

(b)

Fig. (1). (a) Schematic cross section of the completed structure. (b) The current-voltage $(I-V)$ for ohmic check of $\mathrm{Au} / \mathrm{Ni} / \mathrm{p}-\mathrm{ZnO}$ and $\mathrm{Au} / \mathrm{Pt} / \mathrm{Ti} / \mathrm{n}-\mathrm{Si}$ structures, respectively.

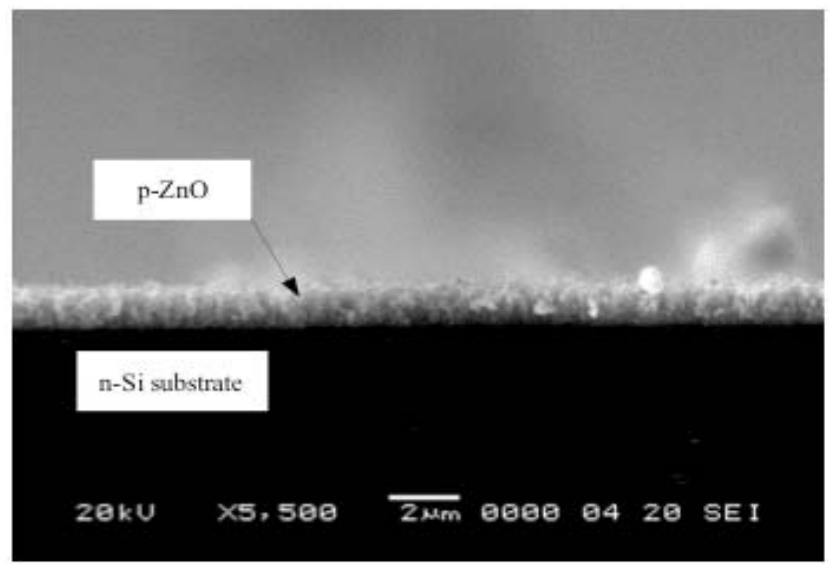

Fig. (2). Cross sectional SEM image of $\mathrm{ZnO} / \mathrm{Si}$ heterostructure.

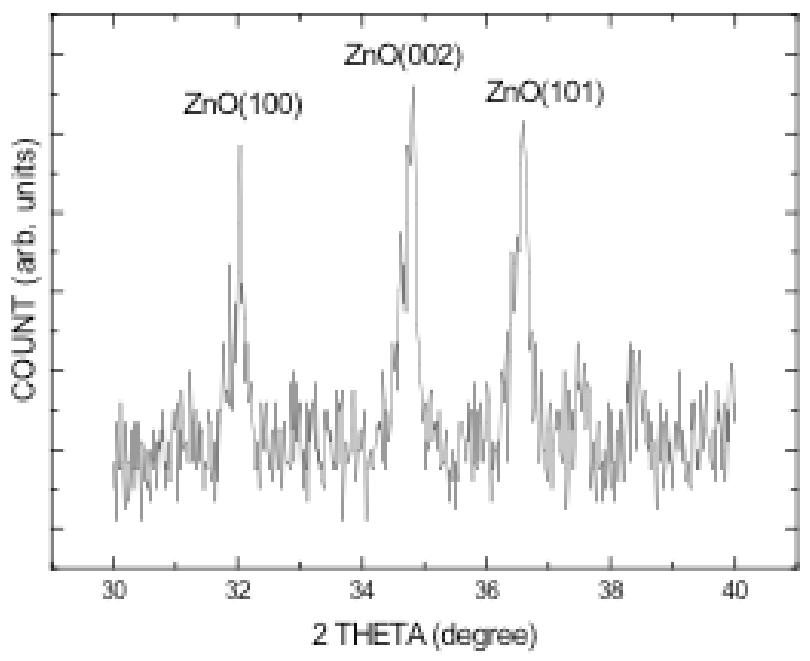

Fig. (3). X-ray diffraction (XRD) pattern of N-In codoped $\mathrm{ZnO}$ film deposited on (111)-oriented Si substrate.

Typical $I-V$ characteristics of the $\mathrm{ZnO} / \mathrm{Si}$ heterostructure photodiodes at room temperature are shown in Fig. (4). To avoid the degeneration of films, voltage was limited from -2 $\mathrm{V}$ to $1 \mathrm{~V}$. The photodiode has a turn-on forward bias of $\sim 0.3$ $\mathrm{V}$. In the reverse direction, the reverse leakage current prior to breakdown is around $10^{-9} \mathrm{~A}$. Fig. (5) shows the plots of the $I-V$ characteristics of the photodiodes measured in the dark (dark current) and under illumination (photocurrent, $\lambda=$ $530 \mathrm{~nm}$ ) at reverse biases from 0 to $1 \mathrm{~V}$. As shown in Fig. (5), it was found the photocurrent approximately $3.9 \times 10^{-7} \mathrm{~A}$ and the dark current was approximately $8.87 \times 10^{-9} \mathrm{~A}$ at a bias of $1 \mathrm{~V}$. Therefore, it was found that a photocurrent to dark current contrast ratio is around two orders of magnitude.

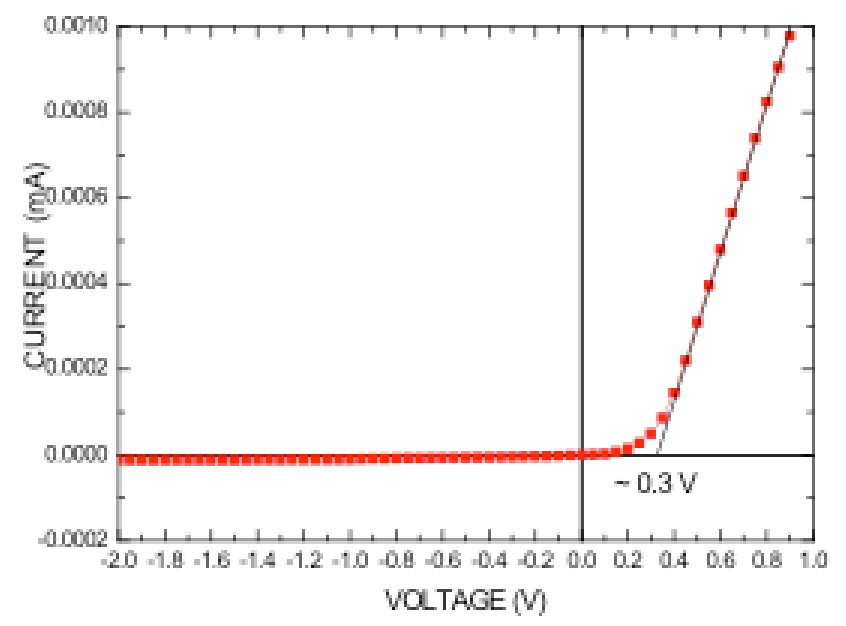

Fig. (4). Typical I-V characteristics of the $\mathrm{ZnO} / \mathrm{Si}$ heterostructure photodiodes.

Fig. (6) shows the plot of responsivity as a function of the wavelength for a $\mathrm{ZnO} / \mathrm{Si}$ heterostructure photodiode at a bias of $1 \mathrm{~V}$. The photodiodes exhibited two higher responsive regions denoted as A and B, respectively. Region A at wavelength approximately from $400 \mathrm{~nm}$ to $700 \mathrm{~nm}$ was owing to $\mathrm{ZnO}$ film absorption occurring through the band-to- 


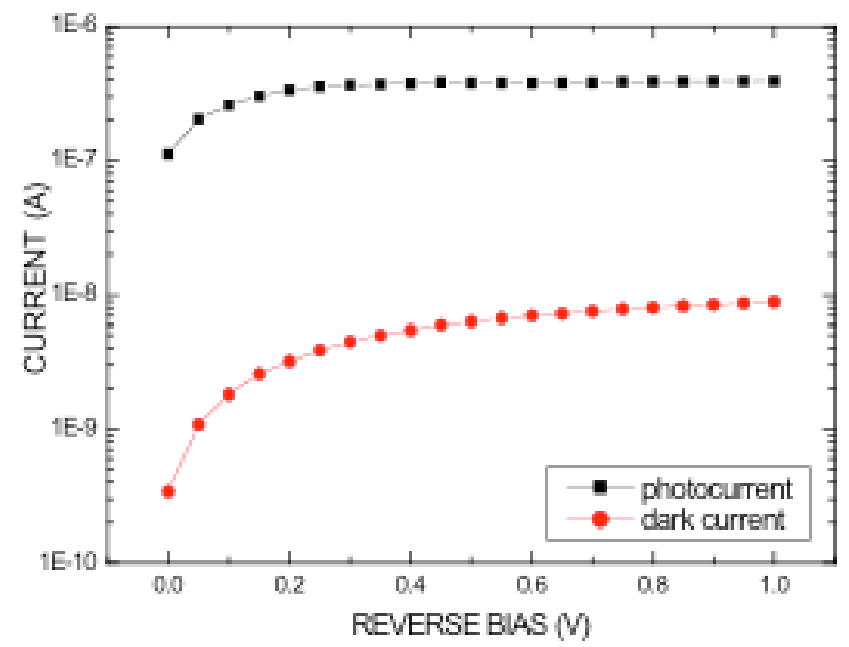

Fig. (5). The dark and illuminated $(\lambda=530 \mathrm{~nm}) I-V$ characteristics of the $\mathrm{ZnO} / \mathrm{Si}$ heterostructure photodiode.

deep level [18], and region B at wavelength approximately from $700 \mathrm{~nm}$ to $1000 \mathrm{~nm}$ was owing to Si substrate absorption occurring through the band edge. Responsivity $R$ can be described as [21]:

$$
R=I_{p h} / P_{i n c}=\eta \frac{q}{h v} \quad(A / W)
$$

where $I_{p h}$ is the photocurrent and $P_{i n c}$ is the incident power, and $\eta, q, v$, and $h$ are the quantum efficiency (QE), electron charge, frequency of incident light, and Planck constant, respectively. Using eq. (1), the values of responsivity and $\mathrm{QE}$ at $530 \mathrm{~nm}$ at biases of $1 \mathrm{~V}$ were $0.204 \mathrm{~A} / \mathrm{W}$ and $47.73 \%$, respectively. The values of responsivity and $\mathrm{QE}$ at $850 \mathrm{~nm}$ at biases of $1 \mathrm{~V}$ were $0.209 \mathrm{~A} / \mathrm{W}$ and $30.49 \%$, respectively. As shown in Fig. (6), in contrast to conventional Si-based photodetectors, the $\mathrm{ZnO}$ film has been improved the responsivity in $\mathrm{UV} / \mathrm{blue}$ region. However, the responsivity was degraded in near infrared region $(700-1100 \mathrm{~nm})$. This result means that the portion of light with higher energy, such as $400-$ $500 \mathrm{~nm}$, was absorbed by $\mathrm{ZnO}$ film and the portion of light with lower energy, such as $800-1000 \mathrm{~nm}$, can completely incident into $\mathrm{Si}$ substrate and was absorbed. However, the responsivity owing to the $\mathrm{ZnO}$ film absorption occurring through the band-to-band did not observe in this work.

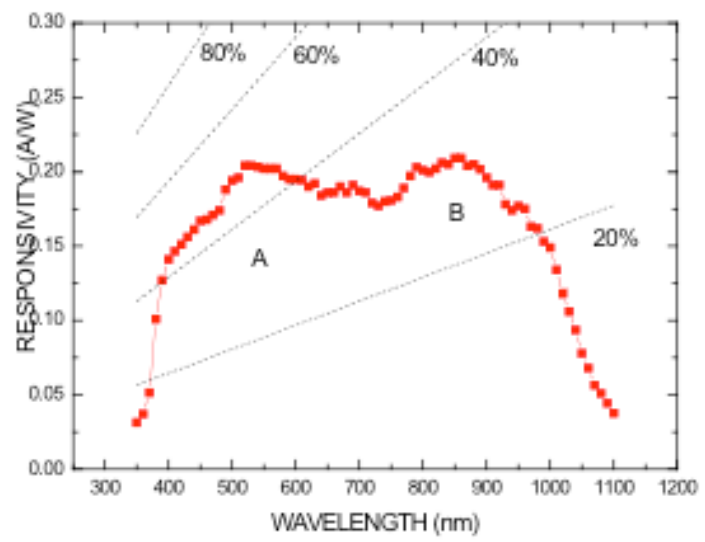

Fig. (6). The responsivity as a function of the wavelength for a $\mathrm{ZnO} / \mathrm{Si}$ heterostructure photodiode at a bias of $1 \mathrm{~V}$.

\section{CONCLUSION}

$\mathrm{ZnO}$ ultraviolet (UV)/visible photodiodes were fabricated. The N-In codoped p-type $\mathrm{ZnO}$ films were deposited on (111)-oriented silicon substrate by ultrasonic spraying pyrolysis method. The photodiodes exhibited two higher responsive regions denoted as $\mathrm{A}$ and $\mathrm{B}$, respectively. Region A at wavelength from $400 \mathrm{~nm}$ to $700 \mathrm{~nm}$ was owing to $\mathrm{ZnO}$ film absorption occurring through the band-to-deep level, and region $B$ at wavelength from $700 \mathrm{~nm}$ to $1000 \mathrm{~nm}$ was owing to $\mathrm{Si}$ substrate absorption occurring through the band edge. In the region $\mathrm{A}$, the values of responsivity and $\mathrm{QE}$ at $530 \mathrm{~nm}$ at biases of $1 \mathrm{~V}$ were $0.204 \mathrm{~A} / \mathrm{W}$ and $47.73 \%$, respectively. In the region $\mathrm{B}$, the values of responsivity and $\mathrm{QE}$ at $850 \mathrm{~nm}$ at biases of $1 \mathrm{~V}$ were $0.209 \mathrm{~A} / \mathrm{W}$ and $30.49 \%$, respectively.

\section{ACKNOWLEDGEMENT}

The authors would like to thank Prof. Y. T. Wang for assistance of spraying system.. Financial support of this work was provided by the National Science Council of the Republic of China under Contract No. NSC 95-2215-E-027091.

\section{REFERENCES}

[1] Zhang XH, Chua SJ, Yong AM, et al. Exciton radiative lifetime in $\mathrm{ZnO}$ nanorods fabricated by vapor phase transport method. Appl Phys Lett 2007; 90: 013107.

[2] Danhara Y, Hirai T, Harada Y, Ohno N. Exciton luminescence of $\mathrm{ZnO}$ fine particles. Phys Stat Sol (c) 2006; 3: 3565-8.

[3] Lim JH, Kang CK, Kim KK, et al. UV electroluminescence emission from $\mathrm{ZnO}$ light-emitting diodes grown by high-temperature radiofrequency sputtering. Adv Mater 2006; 18: 2720-4.

[4] Wei ZP, Lu YM, Shen DZ, et al. Room temperature $p$ - $n$ ZnO blueviolet light-emitting diodes. Appl Phys Lett 2007; 90: 042113.

[5] Leong ESP, Yu SF, Lau SP. Directional edge-emitting UV random laser diodes. Appl Phys Lett 2006; 89: 221109.

[6] Lee $\mathrm{CW}$, Choi $\mathrm{H}$, Oh $\mathrm{MK}$, et al. ZnO-Based cyclodextrin sensor using immobilized polydiacetylene Vesicles. Electrochem Solid State Lett 2007; 10: J1-3.

[7] Abe T, Kashiwaba Y, Onodera S, et al. Homoepitaxial growth of non-polar $\mathrm{ZnO}(11 \overline{2} 0)$ films on off-angle $\mathrm{ZnO}$ substrates by MOCVD. J Crystal Growth 2007; 298: 457-60.

[8] Wang X, Lu YM, Shen DZ, et al. Growth and photoluminescence for undoped and $\mathrm{N}$-doped $\mathrm{ZnO}$ grown on $6 \mathrm{H}-\mathrm{SiC}$ substrate. J Luminescence 2007; 122-123: 165-7.

[9] Park SM, Ikegami T, Ebihara K. Effects of substrate temperature on the properties of Ga-doped $\mathrm{ZnO}$ by pulsed laser deposition. Thin Solid Films 2006; 513: 90-4.

[10] Castañeda L, Maldonado A, Cheang-Wong JC, Terrones M, Olvera $\mathrm{M}$ de la L. Composition and morphological characteristics of chemically sprayed fluorine-doped zinc oxide thin films deposited on Si(1 0 0). Phys B 2007; 390: 10-6.

[11] Kaid MA, Ashour A. Preparation of $\mathrm{ZnO}$-doped Al films by spray pyrolysis technique. Appl Sur Sci 2007; 253: 3029-33.

[12] Bian JM, Li XM, Gao XD, Yu WD, Chen LD. Deposition and electrical properties of N-In codoped $p$-type $\mathrm{ZnO}$ films by ultrasonic spray pyrolysis. Appl Phys Lett 2004; 84: 541-3.

[13] Chen LL, Ye ZZ, Lu JG, Chu PK. Control and improvement of $p$ type conductivity in indium and nitrogen codoped $\mathrm{ZnO}$ thin films. Appl Phys Lett 2006; 89: 252113.

[14] Zheng XG, Li QS, Zhao JP, et al. Photoconductive ultraviolet detectors based on ZnO films. Appl Sur Sci 2006; 253: 2264-7.

[15] Liang S, Sheng H, Lin Y, Huo Z, Lu Y, Shen H. ZnO Schottky ultraviolet photodetectors. J Crystal Growth 2001; 225: 110-3.

[16] Moon TH, Jeong MC, Lee W, Myoung JM. The fabrication and characterization of ZnO UV detector. Appl Sur Sci 2005; 240: 2805 .

[17] Young SJ, Ji LW, Fang TH, Chang SJ, Su YK, Du XL. ZnO ultraviolet photodiodes with Pd contact electrodes. Acta Mater 2007; 55: 329-33. 
[18] Bae HS, Im S. Ultraviolet detecting properties of ZnO-based thin film transistors. Thin Solid Films 2004; 469-470: 75-9.

[19] Oh DC, Suzuki T, Makino H, Hanada T, Ko HJ, Yao T. Electrical properties of $\mathrm{ZnO} / \mathrm{GaN}$ heterostructures and photoresponsivity of ZnO layers. Phys Stat Sol (c) 2006; 3: 946-51.

[20] Veerasamy VS, Amaratunga GAJ, Park JS, Milne WI, MacKenzie HS. Photoresponse characteristics of $n$-type tetrahedral amorphous carbon/p-type Si heterojunction diodes. Appl Phys Lett 1994; 64: 2297-9.

[21] Sze SM. Physics of Semiconductor Devices. $2^{\text {nd }}$ ed. John Willey \& Sons; 1981.

Received: March 23, 2008

Revised: April 21, 2008

Accepted: May 05, 2008

(C) Chen and Pan; Licensee Bentham Open.

This is an open access article distributed under the terms of the Creative Commons Attribution License (http://creativecommons.org/licenses/by/2.5/), which permits unrestrictive use, distribution, and reproduction in any medium, provided the original work is properly cited. 